\title{
Calcium Channel Blockade for Prevention of Recurrent Atrial Fibrillation: Have We Reached a VERDICT?
}

\author{
BRADLEY P. KNIGHT, M.D. \\ From the Division of Cardiology, Department of Internal Medicine, University of Michigan Medical Center, Ann Arbor, MI
}

\section{Editorial Comment}

Despite current advancements in pharmacologic and nonpharmacologic therapy, many patients with persistent atrial fibrillation (AF) continue to be managed with periodic external electrical cardioversion. During 1997, 89,000 inpatients in the United States underwent electrical cardioversion for AF. ${ }^{1}$ Unfortunately, successful restoration of sinus rhythm often is followed by recurrent AF, with most recurrences being within a few weeks. This problem continues to frustrate both patients and physicians. Antiarrhythmic drugs may prolong the time to recurrence, but they commonly are associated with unwanted side effects and proarrhythmia and continue to be associated with an unacceptably high rate of recurrence. Therefore, there is a need for new strategies to reduce recurrences of $\mathrm{AF}$.

The term electrical remodeling has been coined to describe the reversible shortening of atrial refractoriness that occurs during AF. 2,3 Short-term reversible shortening of atrial refractoriness appears to be due to abnormal calcium loading during rapid atrial rates and predisposes patients to recurrent $\mathrm{AF} .{ }^{4} \mathrm{Calcium}$ channel blockade has been shown in experimental studies to prevent the shortening of atrial refractoriness in humans when given before initiation of AF. ${ }^{5}$ In a recent randomized clinical trial, De Simone et al. ${ }^{6}$ treated AF patients with propafenone $900 \mathrm{mg} /$ day for 3 days before and 3 months after elective cardioversion. In addition, each patient was randomized to 1 of 3 groups: verapamil $240 \mathrm{mg} /$ day for 3 days before and 3 months after cardioversion; verapamil $240 \mathrm{mg} /$ day for 3 days before and 3 days after cardioversion; or no verapamil. In their study, $10(30 \%)$ of the 33 patients who were not treated with verapamil had a recurrence of AF within 3 months compared with $5(8 \%) 64$ patients who were treated with verapamil. There was no difference in the recurrence rate among patients who were treated with verapamil for only 3 days after cardioversion compared with patients who were treated for 3 months.

In this issue of the Journal, Van Noord et al. ${ }^{7}$ also tested the hypothesis that oral verapamil prevents recurrent $\mathrm{AF}$ after cardioversion. The study randomized 97 patients who were scheduled to undergo an elective electrical cardioversion for AF to verapamil or digoxin. A strength of the study, and an important difference from the study by De Simone et al., was the omission of all other antiarrhythmic drugs except for $\beta$-adrenergic blockers. The study drug was

J Cardiovasc Electrophysiol, Vol. 12, pp. 770-771, July 2001

Address for correspondence: Bradley P. Knight, M.D., Division of Cardiology, Department of Internal Medicine, University of Michigan Medical Center, 1500 East Medical Center Drive, Ann Arbor, MI 48109. Fax: 313-936-7026; E-mail: bpk@umich.edu started 1 month before and continued 1 month after cardioversion. Initiation of therapy 1 month before cardioversion led to a high dropout rate, primarily because of spontaneous conversions. Using daily transtelephonic monitoring, the authors found no difference in the time to first recurrence of AF within 1 month among patients in the verapamil group compared with patients in the digoxin group (47\% vs 53\%, respectively).

What are the potential explanations for these disappointing results, and why do the findings differ from those of De Simone et al.? One possibility is that the study design was unable to show a benefit of verapamil. The other possibility is that calcium channel blockade has little effect on the prevention of recurrent AF.

Study design issues include the comparison with digoxin, timing of the initiation of verapamil, absence of other antiarrhythmic drugs, small sample size, dose of verapamil, and lower use of $\beta$-adrenergic blockers in the verapamil group. Digoxin was used in this study rather than placebo because patients needed some sort of ventricular rate control. Digoxin has been shown in experimental studies to shorten atrial refractoriness and promote recurrent AF. ${ }^{8}$ Furthermore, the high recurrence rate of 50\% within 1 month in both groups suggests that neither digoxin nor verapamil provided a benefit. Therefore, it is unlikely that the reason no benefit was found in this study was because both digoxin and verapamil prevented recurrences of AF. The authors propose that one reason for the negative results is that calcium channel blockade was given "too late." Perhaps administration of verapamil has little effect on intracellular calcium levels if it is given to a patient after AF is already present. In fact, including the statement "calcium lowering" in the title may be misleading. The authors cite their previous retrospective study that found a lower incidence of recurrent $\mathrm{AF}$ among patients who were chronically taking intracellular calcium-lowering drugs to support the possibility that the verapamil was given too late. ${ }^{9}$ Experimental studies showing that verapamil prevents recurrent $\mathrm{AF}$ involved the administration of verapamil before the initiation or induction of AF. However, if giving verapamil before the onset of AF is the key to success, it is difficult to explain the results of the study by De Simone et al., where verapamil was given only 3 days before cardioversion.

The authors also suggest that the lack of benefit from verapamil in their study may have been due to the absence of concomitant administration of sodium or potassium channel-blocking drugs. The study by De Simone et al. showed that verapamil prevented recurrent $\mathrm{AF}$, but each patient also was treated with propafenone. Verapamil has potassium channel-blocking effects ${ }^{10}$ that may be inadequate when verapamil is given alone, but may be important when given with other antiarrhythmic drugs. Furthermore, adrenergic stimulation has been shown to reverse the effects of sodium 
channel blockers. ${ }^{11}$ There is evidence that quinidine and verapamil have a potent, synergistic inhibitory effect on $\alpha_{1}$-adrenergic receptors. ${ }^{12}$ Further evidence of a positive interaction between verapamil and sodium channel blockers comes from a comparison of two recent studies of the immediate recurrence of $\mathrm{AF}$ after cardioversion. Daoud et al. ${ }^{13}$ found that verapamil reduced immediate recurrences of $\mathrm{AF}$, but their study excluded patients taking amiodarone and included only patients who were receiving propafenone, flecainide, or sotalol. Sticherling et al. ${ }^{14}$ found that verapamil did not prevent immediate recurrences of $\mathrm{AF}$, but patients involved in their study were receiving either amiodarone or no other antiarrhythmic drugs.

The study may have been underpowered with only 43 patients. A study designed with an $80 \%$ power to detect a reduction of recurrent $\mathrm{AF}$ from $50 \%$ to $40 \%$ would require 584 patients. The daily dose of verapamil was stated to range from 120 to $360 \mathrm{mg}$, depending on the heart rate. Unfortunately, the mean doses of verapamil were not reported. It cannot be assumed that administration of verapamil, especially at low doses, resulted in significant reductions in intracellular calcium concentrations. It also is possible that the dose was excessive. It is important to note that four patients randomized to verapamil either discontinued the drug because of worsening heart failure or died of heart failure. Heart failure events did not occur among patients randomized to digoxin. Because atrial stretch appears to shorten atrial refractoriness and promote $\mathrm{AF},{ }^{15}$ it is possible that worsening of heart failure by verapamil minimized its potential benefit. The higher use of $\beta$-adrenergic blockers in the digoxin group (22\%) compared with the verapamil group (10\%) also may have minimized any potential benefit of verapamil, because $\beta$-adrenergic blockers reduce intracellular calcium.

Finally, it is possible that calcium channel blockade cannot prevent recurrent AF. Although electrical changes may be present after conversion of AF, the effect of structural changes may predominate. A study by Everett et al. ${ }^{16}$ in a canine model of $\mathrm{AF}$ found that the vulnerability to easily induced AF persisted in the setting of complete reversal of electrical remodeling but continued morphologic abnormalities. Efforts to reduce the cellular ultrastructural changes that occur during AF may be more effective in preventing recurrences than efforts designed to minimize the reversible electrical changes.

Do calcium channel blockers have a role in the prevention of recurrent AF after cardioversion? So far, the data suggest that verapamil is only effective when it is given in association with sodium or potassium channel-blocking drugs. More studies are needed before calcium channel blockers should be prescribed routinely for patients undergoing cardioversion for AF. We have yet to reach a verdict.

\section{References}

1. Detailed Diagnoses and Procedures, National Hospital Discharge Survey, 1997. Data From the National Health Survey. Publication of the National Center for Health Statistics. ICD-9-CM Codes 99.61 and 99.62.1999. Series 13;145:144.

2. Wijffels MCEF, Kirchhof CJHJ, Dorland R, Allessie MA: Atrial fibrillation begets atrial fibrillation: A study in awake chronically instrumented goats. Circulation 1995;92:1954-1968.

3. Hobbs WJ, Pynn S, Todd DM, Wolfson P, Galloway M, Garratt CJ: Reversal of atrial electrical remodeling after cardioversion of persistent atrial fibrillation in humans. Circulation 2000;14:1145-1151.

4. Daoud EG, Bogun F, Goyal R, Harvey M, Man KC, Strickberger SA, Morady F: Effect of atrial fibrillation on atrial refractoriness in humans. Circulation 1996;94:1600-1606.

5. Daoud EG, Knight BP, Weiss R, Bahu M, Paladino W, Goyal R, Man KC, Strickberger SA, Morady F: Effect of verapamil and procainamide on atrial fibrillation-induced electrical remodeling in humans. Circulation 1997;96:1542-1550.

6. De Simone A, Stabile G, Vitale DF, Turco P, Di Stasio M, Petrazzuoli F, Gasparini M, De Matteis C, Rotunno R, Di Napoli T: Pretreatment with verapamil in patients with persistent or chronic atrial fibrillation who underwent electrical cardioversion. J Am Coll Cardiol 1999;34: 810-814.

7. Van Noord T, Van Gelder IC, Tieleman RG, Bosker HA, Tuinenburg AE, Volkers C, Veeger NJGM, Crijns HJGM: VERDICT: The Verapamil versus Digoxin Cardioversion Trial: A randomized study on the role of calcium lowering for maintenance of sinus rhythm after cardioversion of persistent atrial fibrillation. J Cardiovasc Electrophysiol 2001;12:766-769.

8. Sticherling C, Oral H, Horrocks J, Chough SP, Baker RL, Kim MH, Wasmer K, Pelosi F, Knight BP, Michaud GF, Strickberger SA, Morady F: Effects of digoxin on acute, atrial fibrillationinduced changes in atrial refractoriness. Circulation 2000;102: 2503-2508.

9. Tieleman RG, Van Gelder IC, Crijns HJGM, De Kam PJ, Van den Berg MP, Haaksma J, Van der Woude HJ, Allessie MA: Early recurrences of atrial fibrillation after electrical cardioversion: A result of fibrillation-induced electrical remodeling of the atria? J Am Coll Cardiol 1998;31:167-173.

10. Gotoh Y, Imaizumi Y, Watanabe M, Shibata EF, Clark RB, Giles WR: Inhibition of transient outward $\mathrm{K}^{+}$current by DHP $\mathrm{Ca}^{2+}$ antagonist and agonists in rabbit cardiac myocytes. Am J Physiol 1991;257: H1737-H1742.

11. Calkins H, Sousa J, el-Atassi R, Schmaltz S, Kadish A, Morady F. Reversal of antiarrhythmic drug effects by epinephrine: Quinidine versus amiodarone. J Am Coll Cardiol 1992;19:347-352.

12. Shibata K, Hirasawa A, Foglar R, Ogawa S, Tsujimoto G: Effects of quinidine and verapamil on human cardiovascular alpha1-adrenoceptors. Circulation 1998;97:1227-1230.

13. Daoud EG, Hummel JD, Augostini R, Williams S, Kalbfleisch SJ: Effect of verapamil on immediate recurrence of atrial fibrillation. J Cardiovasc Electrophysiol 2000;11;1231-1237.

14. Sticherling C, Oral H, Chough SP, Baker RL, Wasmer K, Kim MH, Pelosi F, Michaud GF, Knight BP, Strickberger SA, Morady F: Intravenous ibutilide is more effective in preventing immediate recurrence of atrial fibrillation after transthoracic cardioversion than intravenous verapamil. (Abstract) PACE 2000;23:577.

15. Tse HF, Pelosi F, Oral H, Knight BP, Strickberger SA, Morady F: Effects of simultaneous atrioventricular pacing on atrial refractoriness and atrial fibrillation inducibility: Role of atrial mechanoelectrical feedback. J Cardiovasc Electrophysiol 2001;12:43-50.

16. Everett TH 4th, Li H, Mangrum JM, McRury ID, Mitchell MA, Redick JA, Haines DE: Electrical, morphological, and ultrastructural remodeling and reverse remodeling in a canine model of chronic atrial fibrillation. Circulation 2000;102:1454-1460 